\title{
Pele Negra/Vermelha, Máscaras Brancas: Contribuições à Descolonização das Teorias do Reconhecimento ${ }^{1}$
}

\author{
Marcos de Jesus Oliveira \\ Doutor em Sociologia. Docente do Programa de Pós-Graduação Interdisciplinar em Estudos Latino-Americanos (PPG-lela) \\ da Universidade Federal da Integração Latino-Americana (Unila). http://lattes.cnpq.br/2883020573246390. \\ https://orcid.org/0000-0002-0478-3941.oliveiramark@yahoo.com.br
}

RESUMO

O objetivo do presente trabalho é apresentar alguns dos limites das teorias do reconhecimento quando pensadas desde a perspectiva pós-colonial e em contextos não europeus. No percalço deste objetivo, dividiu-se o texto em quatro partes, iniciando-o com uma breve exposição da problemática para, em seguida, discutir a proposta de Frantz Fanon como uma das mais paradigmáticas e influentes nos estudos pós-coloniais. Feito isso, passa-se à contribuição de Glean Sean Coulthard, com o intuito de aprofundar alguns dos problemas das correntes hegemônicas sobre o reconhecimento. Ao final, discute-se os desafios colocados pelas teorias pós-coloniais às teorias do reconhecimento na superação do "déficit colonial" das tendências hegemônicas.

Palavras-chave: Reconhecimento. Colonialidade. Fanon. Coulthard.

\section{BLACK/RED SKIN, WHITE MASKS: CONTRIBUTIONS TO THE DECOLONIZATION OF RECOGNITION THEORIES}

\section{ABSTRACT}

The aim of this essay is to present some of the limits of the theories of recognition when thought from a postcolonial perspective and in non-European contexts. Following this objective, the text was divided into four parts: we begin with a brief exposition of the hegemonic visions on recognition and then discuss Frantz Fanon's proposal as an important one in contemporary postcolonial debates. Next, Glean Sean Coulthard's contribution is presented in order to highlight some of the problems of hegemonic conceptions on recognition. Finally, we discuss the challenges posed by postcolonial theories to the theories of recognition in overcoming the so-called "colonial deficit" of hegemonic tendency.

SUMÁRIO

Keywords: Recognition. Coloniality. Fanon. Coulthard.

1 Introdução. 2 Os condenados da terra e os limites das teorias do reconhecimento segundo Frantz Fanon. 3 As (des)continuidades do colonialismo no marco do Estado liberal segundo Glean Sean Coulthard. 40 "déficit colonial" e a descolonização das teorias do reconhecimento. 5 Referências.

Recebido em: 9/10/2017

Aceito em: 29/5/2020

\footnotetext{
1 A primeira versão deste ensaio foi lida no painel “Epistemologias do Sul: Rumo à descolonização das estruturas de saber/poder nas Relações Internacionais" do 4은 Seminário de Relações Internacionais (Abri), realizado nos dias 27 e 28 de setembro de 2018 na Universidade Federal da Integração Latino-Americana.
} 


\section{Humanos e \\ Democracia}

\section{INTRODUÇÃO}

Inúmeras correntes e tradições teóricas têm criticado a concepção de sujeito cartesiano elaborado pela chamada modernidade filosófica ocidental. Em "Fenomenologia do Espírito", Friedrich Hegel (2014), na aurora do século 19, insurgia com um trabalho de fissura na concepção cartesiana de sujeito já evidente nos chamados "anos de Jena", ensejando um horizonte crítico em relação ao monismo subjetivo de Descartes, embora, é bom lembrar, ainda compartilhasse com ele certas premissas, posto que ambos faziam parte de um projeto histórico-filosófico semelhante. Nos últimos 50 anos, cresceram as discussões sobre o conflito social a partir do paradigma intersubjetivo aberto por Hegel, sobretudo com o conceito de reconhecimento de seus primeiros escritos filosóficos ou, ainda, com a dialética do senhor/ escravo de anos mais tarde.

Charles Taylor, Axel Honneth, Nancy Fraser, Will Kymlicka, Michael Sandel, Rainer Foster e Judith Butler, ${ }^{2}$ não obstante as diferenças e divergências, representam alguns dos esforços teóricos contemporâneos de reconstrução do paradigma do reconhecimento. Seus trabalhos têm realizado, de distintas formas, e, por vezes, em confronto aberto, críticas aos limites e às possibilidades do reconhecimento como categoria analítica, revelando a produtividade de tal paradigma. A despeito desse esforço, parecem ainda falar desde um ponto de vista eurocentrado, ainda que alguns deles tenham se envolvido na discussão dos direitos e reivindicações de indígenas e/ou de sujeitos em situação diaspórica. Aqui pretende-se operar um "giro na geografia da razão" (GORDON, 2006), trazendo as críticas aos limites do paradigma do reconhecimento ou, mesmo, de sua impossibilidade em contextos não europeus ou em contextos (pós)coloniais, sobretudo pelas contribuições de Frantz Fanon e Glean Sean Coulthard.

Situando-se, portanto, no interior dos debates sobre as teorias do reconhecimento, o presente ensaio pretende identificar alguns dos limites dessas teorias quando pensadas desde a perspectiva (pós)colonial e em contextos não europeus, onde têm sido hegemonicamente elaboradas, assumindo a premissa dusseliana, segundo a qual o "ego conquiro" antecede ao "ego cogito" cartesiano como condição de possibilidade da modernidade ocidental e, portanto, das teorias do reconhecimento. No percalço deste objetivo, dividiu-se o texto em quatro partes. Ademais desta sucinta introdução, o trabalho segue com uma breve exposição da problemática com ênfase na tese de que, a despeito do esforço de inúmeros/as pensadores/ as contemporâneos/as na redefinição do paradigma do reconhecimento, estes/as veem a colonização como um "mero" acontecimento histórico sem implicações teórico-metodológicas.

Em seguida, discute-se a proposta de Frantz Fanon como uma das mais paradigmáticas e influentes nos estudos (pós)coloniais, destacando sua contribuição acerca da existência de uma esfera sub-ontológica à qual sujeitos racializados estão circunscritos e que bloqueia o movimento de reconhecimento de suas subjetividades. Feito isso, passa-se aos aportes teóricos de Glean Sean Coulthard, com o intuito de evidenciar que a ausência de um debate sobre o colonialismo contribui para sua continuidade nas práticas estatais contemporâneas de reconhecimento de grupos historicamente marginalizados e/ou excluídos. Ao final, enfatizam-se

\footnotetext{
2 Para não sobrecarregar o texto, cito aqui apenas alguns trabalhos mais representativos: Charles Taylor (1994), Axel Honneth (2009), Nancy Fraser (2001), Will Kymlicka (1989), Michael Sandel (2011), Rainer Foster (2010) e Judith Butler (2015).
} 
os desafios colocados pelas teorias (pós)coloniais às teorias do reconhecimento na superação do que qualifico como "déficit colonial" das tendências hegemônicas. Conforme se argumentará, o déficit está em não teorizar a colonialidade como a face necessária da modernidade, a relação entre modernidade e extermínio/terror.

\section{OS CONDENADOS DA TERRA E OS LIMITES DAS TEORIAS DO RECONHECIMENTO SEGUNDO FRANTZ FANON}

Em "1492: o encobrimento do outro (a origem do mito da modernidade)", Enrique Dussel (1993) elabora a tese segundo a qual o cogito cartesiano só se tornou possível em razão da conquista da América. Sem o acúmulo material permitido pelos primeiros séculos de exploração do continente latino-americano e do Caribe, Descartes não poderia ter publicado, na Holanda, seu Discurso do método em 1637. O conquiro é, portanto, condição de possibilidade do cogito. Esse aspecto do pensamento de Dussel interessa porque põe em cena uma dimensão não teorizada pelos saberes europeus, ou melhor, eurocêntricos: a colonialidade. Embora o conceito seja comumente atribuído a Aníbal Quijano (2014), parte de sua elaboração está atrelada a uma série de debates construídos por décadas no continente. W. E. B. Du Bois, Aimé Césaire, Angela Davis, Abdias Nascimento, Lélia Gonzalez , ${ }^{3}$ apenas para citar alguns, revelaram, de distintos modos e com diferentes ênfases, certa indissociabilidade entre modernidade e extermínio, ou, em outras palavras, entre modernidade e colonialidade.

Não se pretende imprimir aos autores citados o título de "pais-fundadores" da ideia de colonialidade avant la lettre, instituindo um cânone. A própria ideia de "origem" e de "fundação" deve ser questionada (cf. DERRIDA, 2008) se quisermos construir genealogias informadas por uma problematização geopolítica e corpo-política do conhecimento. O gesto almeja, antes de mais nada, colocar em cena que os conceitos não são meras elaborações solitárias de determinados sujeitos, exceto na ficção cartesiana do ego cogito ou na kantiana do gênio do romantismo alemão, mas integram uma teia de debates, de disputas e de práticas de saber/poder cuja referência é necessária para elucidar a inteligibilidade pela qual seu sentido é possível. Para dizê-lo de outro modo, a escolha dos autores e autoras aqui apresentadas é resultado de uma trajetória pessoal de leitura cujos sentido e significado são indissociáveis de uma relação com uma comunidade mais ampla de debate, de uma geopolítica do conhecimento e, portanto, das condições materiais e simbólicas de quem fala desde a periferia do mundo globalizado e racializado.

Posto isto, a colonialidade, entendida como subjugação do outro, seria uma dimensão coconstitutiva da história europeia embora seja repudiada por sua retórica. Descartes jamais reconheceu a conquista - leia-se também violência, extermínio e exploração dos povos ameríndios, africanos e asiáticos - como condição de seu fazer filosófico. A elaboração de uma reflexão geolocalizada, de uma perspectiva desde o Sul global, pretende trazer à tona os elementos repudiados para que disso seja possível entrever o mundo desde outros lugares, desde outras geografias da razão, memórias e corporalidades. Quando Dussel (1996) recupera a noção de totalidade de Emmanuel Lévinas no contexto de sua filosofia da libertação, o faz

\footnotetext{
3 Para não sobrecarregar o texto, cito aqui apenas alguns trabalhos mais representativos: W. E. B. Du Bois (1999), Aimé Césaire (1978), Angela Davis (2016), Abdias Nascimento (2016) e Lélia Gonzalez (1988).
} 


\section{Humanos e \\ Democracia}

com o intuito de apontar os limites do pensamento europeu. Os povos latino-americanos, assim como os asiáticos e africanos, habitam esse espaço para além da totalidade e da completude europeia. A analética - não prevista pela dialética hegeliana - é o momento pelo qual se pode interpretar a realidade dos povos do Sul, sobretudo porque parte da experiência cotidiana do/a oprimido/a e de sua dominação desde o processo de conquista.

O processo de colonização e a raça como categoria fundamental da modernidade (cf. QUIJANO, 2014), apontados anteriormente, estão ausentes dos debates sobre reconhecimento. Nem mesmo Hegel, cuja dialética do senhor/escravo parece ter sido retirada do impacto da Revolução Haitiana no início do século 19 (cf. BUCK-MORSS, 2013), preocupou-se em teorizar a questão, transformando-a em categoria abstrata desde a qual compreende o processo de constituição da subjetividade e sem referência à concretude da revolta dos "jacobinos negros" (JAMES, 2010). A produção teórica de Frantz Fanon não passou incólume à problemática da colonização; seu saber/fazer teórico constrói-se por uma corpo-política, em que a memória corporal assume centralidade: "Ô meu corpo, faça sempre de mim um homem que questiona!" (FANON, 2008, p. 191).

Sem dúvida, uma das maiores contribuições de Fanon está em tratar a colonização como uma categoria de análise explicativa com implicações teórico-metodológicas importantes e singulares, e não como um "mero" acontecimento histórico datado e acabado. Dentre as consequências está, certamente, a necessidade de autorreflexividade do pesquisador e da pesquisadora para que o mecanismo colonizador não colonize a teoria pela qual se pretende explicar a colonização (cf. GORDON, 2008). A descrição da sociogênese pela qual homens e mulheres se constituem como sujeitos de uma dada realidade histórico-social, é uma das estratégias para contornar os meandros que condicionam o horizonte das experiências do colonizado e suas chances de libertação.

Segundo Fanon (1968), o mundo colonial é dividido em dois, duas zonas: a do colonizado e a do colonizador. As fronteiras estão guardadas pelas forças policiais cuja principal estratégia para preservar sua integridade simbólica e material é a violência física direta e frontal. São dois mundos tão irredutivelmente diferentes que seu maniqueísmo funda uma ontologia irreconciliável, uma diferença incomensurável com a qual se pretende garantir a submissão de um em relação ao outro. Esses universos simbólicos e materiais paralelos coexistem da necessidade de dominação e exploração, mas não se misturam ou se tocam, não permitem um movimento de síntese, no sentido dialético do termo. A mistura é algo socialmente condenado e condenável. Os sujeitos que habitam essas zonas estão fadados a ficar nelas; o trânsito não é autorizado, uma vez que impossível por conta da irredutibilidade de sua própria configuração.

Dialogando com a dialética cuja discussão estava em voga nas décadas de 50 e 60 na América Latina e Caribe e também na França, Fanon se esforçará por mostrar os limites desta dialética quando pensada desde contextos coloniais. No mundo colonial maniqueísta não há dialética, pois o negro escravizado está destituído de toda sua humanidade, o que impede movimento e transformação:

A crítica de Fanon à circularidade ontológica da dialética hegeliana do senhor/escravo sua presumida reciprocidade, simetria e reversibilidade - prepara o cenário não para rejeitar a dialética, mas sim para a descolonização total e a reconstrução da abordagem de Hegel desde o início. Ou mais precisamente, desde abaixo do fundamento: diagnosticar a 
existência de um domínio sub-ontológico ao qual os racializados são condenados aponta para a necessidade de luta pré-dialética, para uma violência contra-ontológica que cria a base para a oposição verdadeiramente dialética (CICCARIELLO-MAHER, 2017, p. 70).

Hegel (2010), em "Filosofia da história", recusa-se a tratar do continente africano em sua discussão sobre a história-mundo, preferindo centrar-se no apogeu onde esta história supostamente se desenvolve - a Europa -, ou, mais especificamente, a Alemanha, pois, para ele, os africanos ainda não saíram do estágio da natureza. O filósofo está, ainda que não reconheça, relegando os africanos à zona dos colonizados, à zona daqueles destituídos de humanidade, a uma subontologia. Na dialética da manifestação do espírito absoluto, o continente africano não tem nada a agregar porque é ontologicamente inferior, restando a ele apenas uma assimilação forçada ou uma submissão inquestionável. Fanon aponta, pois, os limites da dialética no reconhecimento de sujeitos racializados, posto que, décadas depois de Hegel escrever sua obra mais famosa - "Fenomenologia do espírito" (1807) -, acontecerá o Congresso de Berlin (1878), em que as potências europeias partilham a África entre si, atestando o sentido instrumental dos povos do continente. De acordo com Fanon (1968),

A zona habitada pelos colonizados não é complementar da zona habitada pelos colonos. Estas duas zonas se opõem, mas não em função de uma unidade superior. Regidas por uma lógica puramente aristotélica, obedecem ao princípio da exclusão recíproca: não há conciliação possível, um dos termos é demais (p. 28).

Na visão de Fanon, tal como apresentada por George Ciccariello-Maher (2017), a dialética hegeliana pressupõe reciprocidade, circularidade e simetria, além de estar ancorada em uma concepção teleológica, progressiva e determinista de mundo. A dialética hegeliana encena a força de uma contingência histórica que quer se tornar necessária ou, para dizê-lo de outro modo, trata-se da necessidade europeia em se posicionar não apenas como potência econômica e militar, mas também epistêmica, em construir uma ordem simbólica que afirme e confirme sua superioridade. A dialética hegeliana é a dialética do ponto de vista do senhor que se crê soberano e independente de uma referência ao outro, ou melhor:

O nome dado à dialética do senhor/escravo de Hegel é enganador, já que não começa nem com mestres nem com escravos. Em vez disso, prevê uma autoconsciência simples em busca de uma autoconsciência mais verdadeira, autonomia e auto-suficiência (Selbstständigkeit). O caminho para a autoconsciência passa inevitavelmente pelo outro, que, como tal, parece ser magneticamente: uma ameaça a ser superada, mas não evitada (CICCARIELLO-MAHER, 2017, p. 54).

Provincializar (cf. CHAKRABARTY, 2000) o paradigma do reconhecimento significa evidenciar que a dialética é corpo-localizada e geossituada, uma dialética cuja pretensão de universalidade deixa revelar, inadvertidamente, sua "vontade de poder" e seu querer teleológico por produzir certos efeitos sobre a realidade. Ao ser obstruída em contextos coloniais, a dialética torna-se uma retórica europeia cuja finalidade é criar uma ilusão de movimento, posto que os sujeitos escravizados e, portanto, racializados, não são considerados propriamente humanos, relegados à zona do mundo colonial destinada a sujeitos destituídos de humanidade. A violência como forma de libertação parte da ideia de que a entrada do colonizado na dialética do reconhecimento se faz por uma ruptura. Algo assim levou Fanon a criticar os movimentos nacionalistas africanos que não traziam em seu bojo a radicalização do huma- 


\section{Democracia}

Humanos e

nismo. Os movimentos de libertação nacional na África corriam o risco de reproduzir os erros que criticavam, caso não conseguissem operar uma ruptura da ordem que limita a entrada do negro na dialética do reconhecimento.

\section{AS (DES)CONTINUIDADES DO COLONIALISMO NO MARCO DO ESTADO LIBERAL SEGUNDO GLEAN SEAN COULTHARD}

De imediato, o título Pele vermelha, máscaras brancas, de Glean Sean Coulthard (2014), sugere uma alusão ao famoso Pele negra, máscaras brancas de Fanon, com o qual dialogará intensamente; seu subtítulo, rejeitando a política colonial do reconhecimento, uma crítica veemente a um modelo de política do reconhecimento existente cuja promessa de consideração e de respeito é o mecanismo pelo qual o Estado liberal contemporâneo coopta as demandas e reivindicações dos povos e comunidades indígenas do Canadá, acomodando-as a seu ímpeto colonialista. A imagem oferecida é, portanto, bem distante daquela consagrada pela visão idílica oferecida pelas teorias tradicionais do reconhecimento, situando alguns dos limites das correntes hegemônicas, sobretudo no marco do Estado moderno/colonial e seus desdobramentos contemporâneos.

No interior deste debate, Pele vermelha, máscaras brancas é um ponto de inflexão interessante, sobretudo porque sai da polarização entre "liberais" versus "comunitaristas", quando o debate sobre o reconhecimento se vê, muitas vezes, limitado, e cujos contornos impedem entrever o caráter colonial das formações estatais contemporâneas. Além da influência fanoniana, suas contribuições alinham-se, em alguma medida, aos trabalhos de Taiaiake Alfred, cujo pensamento combativo é uma forma de insurgência contra os legados coloniais contemporâneos de violência a indígenas. ${ }^{4} \mathrm{O}$ livro de Coulthard está dividido em cinco capítulos, ademais da introdução e da conclusão. No final, apresenta, de modo resumido, cinco teses sobre o ativismo indígena do futuro, e é por elas que se pretende aqui demonstrar os aportes teóricos à rediscussão das teorias do reconhecimento. A conclusão é aberta da seguinte forma:

Ao escrever este livro, propus-me a problematizar a suposição cada vez mais comum de que a relação colonial entre povos indígenas e o Estado canadense pode ser reconciliada através da "política de reconhecimento" liberal. Caracterizei a "política de reconhecimento" como uma abordagem baseada no reconhecimento para conciliar as afirmações dos povos indígenas com a soberania do Estado colonial por meio da acomodação de reivindicações relacionadas à identidade indígena através da negociação de assentamentos em detrimento de questões como terra, desenvolvimento econômico e autogoverno. Argumentei que essa orientação para a reconciliação da nacionalidade indígena com a soberania do Estado ainda é colonial na medida em que permanece estruturalmente comprometida com a desapropriação de povos indígenas de nossas terras e autoridade autodeterminada (COULTHARD, 2014, p. 151, grifos do autor).

Confira, por exemplo, TAIAIAKE, 2005, 2009, ou TAIAIAKE; REGAN, 2011. 
Mais adiante, Coulthard explica que as formas de violência assumidas pelas formações sociais modernas contemporâneas não são necessariamente marcadas pelo uso da força ou pela coerção, mas por formas mais sutis de extermínio físico e simbólico do outro. Nem por isso essas formas são menos ruins e menos nefastas em suas consequências:

E, finalmente, argumentei que as formas de poder colonial associadas à acumulação primitiva não precisam ser entendidas como estritamente coercitivas, repressivas ou de natureza explicitamente violenta; em vez disso, as práticas de expropriação central à manutenção do colonialismo dos colonos em contextos democráticos liberais, como o Canadá, dependem muito do caráter de produção do poder colonial como acontece com a autoridade coercitiva do Estado colonizador (COULTHARD, 2014, p. 152).

A primeira tese "Sobre a necessidade de uma ação direta" fala da necessidade de práticas mais incisivas de luta por libertação baseada na premissa de que, conforme Coulthard mesmo afirma, citando Fanon, o mestre não quer o reconhecimento por parte do escravo, mas trabalho. Tal compreensão ancora-se na ideia de que a política liberal de reconhecimento é cúmplice de práticas de expropriação das terras indígenas e da negação de suas existências singulares. O reconhecimento estatal liberal não implica mudanças ou transformações em sua estrutura, mas uma acomodação das demandas e reivindicações indígenas àquela estrutura colonial. Para dizê-lo de outro modo, o Estado liberal contemporâneo caracteriza-se por um conjunto de mecanismos pelos quais o genocídio físico e cultural daquele que, desde a formação da modernidade, é considerado seu outro, se manifesta.

Há, conforme Coulthard, três núcleos argumentativos contra as formas de insurgência indígena mais incisivas e mais assertivas com o intuito de bloqueá-las ou impedi-las. O primeiro ressalta que, para garantir e assegurar os direitos das comunidades indígenas, a negociação e o diálogo não violento são sempre os melhores caminhos. O segundo núcleo argumenta que o uso de força é uma forma de alienação indígena, contribuindo para aumentar a hostilidade de grupos que, a princípio, poderiam trabalhar pela sua causa. Finalmente, o último núcleo descreveria a luta indígena de pendor mais contundente, na esteira de uma perspectiva nietzschiana, como essencialmente reativa. Para estes, o ressentimento e a raiva são apenas manifestações da incapacidade dos fracos de agir e de transformar sua própria realidade, de ser propositivo. Para Coulthard, o essencial seria canalizar tais sentimentos, uma vez que também são portadores de moralidade, motores essenciais à luta por justiça e por autonomia indígenas.

"Capitalismo, não mais" representa uma incisiva e incontornável crítica ao modo de produção capitalista. Algo assim é importante de relatar, uma vez que os estudos (pós)coloniais são, amiúde, acusados de não levar o capitalismo a sério. Em suas melhores expressões, a pós-colonialidade nunca renunciou a uma discussão crítica em relação à exploração capitalista; propôs-se apenas a pensá-la desde um marco teórico mais amplo ou desde sua relação com fenômenos diversos sem reduzi-la a manifestações epifenomênicas. Para Coulthard, a "acumulação primitiva" de Marx não é apenas um mero estágio inicial do capitalismo, mas algo que se reatualiza constantemente nos diferentes momentos de sua trajetória de acumulação. Nesse sentido, a saída é a construção de economias alternativas à produção capitalista, bem como o fortalecimento de mecanismos contra a exploração das pessoas. Coulthard tem, 


\section{Humanos e \\ Democracia}

em seu horizonte, os inúmeros desafios implicados nessa sua escolha. A demissão de formas capitalistas não é um mero ato da vontade, envolvendo a construção de relações de solidariedades e de redes de trocas em âmbitos nacional e transnacional.

Ao descrever o processo histórico pelo qual os indígenas têm suas terras usurpadas pelos colonizadores, a tese exposta em "Expropriação e soberania indígena na cidade" (COULTHARD, 2014) reitera alguns dos elementos aludidos na defesa de formas de insurgência indígena. Tal processo não se finda com a independência ou com a construção do Estado-nação cujo locus de controle político passa a ser interno. Conforme colocado anteriormente, a contribuição de Coulthard está em mostrar como o processo de expropriação indígena continua e como as políticas do reconhecimento no marco do Estado liberal tende a impedir a construção de uma autonomia indígena. Atualmente, inúmeros indígenas vivem na cidade; no entanto, o discurso supremacista branco operou uma assimilação por meio de processos de higienização social e cultural. Isso contribuiu para ofuscar as relações entre "colonizadores" e "colonizados", destituindo a luta de seu ímpeto por uma transformação mais radical.

"Justiça de gênero e descolonização" (COULTHARD, 2014) coloca, no cerne da discussão, a necessidade de avaliar a violência simbólica e misógina do colonizador e das sociedades ocidentais de modo mais amplo. Esse processo histórico, no qual as mulheres indígenas têm sido vítimas, acentua o fosso de assimetrias que marca a vida e a existência indígenas. Para Coulthard, as mulheres indígenas sofrem com inúmeras privações sociais e econômicas; algumas delas bastante elementares, como a falta de acesso à água potável. A necessidade de uma revolução cultural como resistência às diferentes formas de violência e desigualdades de gênero é parte da estratégia de luta, na medida em que o simbólico que ordena as relações sociais de gênero tende a privilegiar os homens brancos canadenses.

Fechando sua linha argumentativa com "Para além do Estado-nação" (COULTHARD, 2014), o Estado moderno é tomado como uma forma política, uma condição necessária ao processo de acumulação capitalista. A forma estatal contemporânea reafirma a ordem da desigualdade, uma vez que o Estado não representa apenas aquele que detém o monopólio da violência física legítima, mas também simbólica, posto que inseparáveis. Violência física e simbólica misturam-se e fazem parte dos processos de exclusão de determinados grupos, populações ou indivíduos, pois seu funcionamento ancora-se em uma administração da diferença e da identidade em perspectiva de conciliação. A superação da dominação branco colonial-burguesa implica a política como "prática decolonial, emancipadora de gênero, e lei e autoridade soberana sobre estruturas econômicas alternativas de não exploração fundamentada na reformulação crítica das melhores tradições legais e políticas indígenas" (COULTHARD, 2014, p. 179).

\section{0 “DÉFICIT COLONIAL" E A DESCOLONIZAÇÃO DAS TEORIAS DO RECONHECIMENTO}

Situar o Estado moderno no horizonte histórico do processo de colonização e do racismo impõe inúmeros desafios à discussão sobre o reconhecimento de sujeitos racializados. Seria o Estado moderno/colonial capaz de garantir o reconhecimento das identidades indígenas quando este foi historicamente instituído para manter as fronteiras muito bem delimitadas entre zonas do colonizado e do colonizador? O agente histórico da civilização branca cristã 
ocidental seria capaz de ouvir outras gramáticas da justiça e da dignidade humana? Pode o subalterno falar diante de um tribunal do reconhecimento forjado pelo conquiro/cogito? Estas são problemáticas às quais quem trabalha com a perspectiva (pós)colonial não podem se furtar, posto que, historicamente, o Estado é perpetrador do extermínio daqueles que são considerados o outro da nação: indígenas e afrodescendentes, sobretudo.

As teorias de Fanon e Coulthard, mas não apenas deles, trazem inúmeros desafios para os debates contemporâneos sobre as teorias e políticas do reconhecimento, ultrapassando os limites a que tais discussões se viram circunscritas nas últimas décadas, sobretudo por conta da polarização em torno de "liberais" e "comunitaristas". A entrada do subalterno na dialética do reconhecimento implica situar a sociedade branco-colonial-burguesa em suas inúmeras estratégias para assegurar seus privilégios históricos pelos quais a ordem da desigualdade e da violência se reproduz. O marco teórico-político pós-colonial situa as formações sociais modernas em sua intrínseca relação com o colonialismo e o imperialismo, tornando factível compreender o processo pelo qual as lutas por justiça e por igualdade acabam sendo acomodadas às estruturas de dominação.

Um conjunto de pensadores consagrados no âmbito da discussão sobre reconhecimento têm chamado a atenção para a necessidade de superação do "déficit sociológico" (cf. HONNETH, 1990, 2015) na compreensão das dinâmicas de conflito na atualidade, bem como das energias utópicas e emancipadoras do presente. A despeito disso, parecem não ter conseguido dar uma resposta totalmente adequada, pois o que está em jogo é justamente o que conta como "déficit". Desde a perspectiva das teorias pós-coloniais aqui apontadas, o déficit está em não teorizar a colonialidade como a face necessária da modernidade, a relação entre modernidade e extermínio/terror. Fazê-lo significa qualificar o "déficit sociológico" como um "déficit colonial", com o qual se pode abrir novos horizontes de interpretação acerca da temática do reconhecimento, seus limites e seus desafios.

Os pensadores aqui brevemente apresentados são, certamente, caminhos possíveis para a realização de tal empreitada. Todos eles apresentam, de distintos modos e com ênfases diversas, aportes teóricos essenciais para pensar a "linha de cor", o problema central do século 20 na visão de W. E. B. Du Bois (1999). O desafio da linha de cor, ou melhor, da linha colonial, segue no século 21 com nuances próprias e matizes específicos, posto que, embora os processos de descolonização tenham se efetivado, a divisão maniqueísta e racializada do mundo continua como efeito mais duradouro e deletério na conformação de instituições e práticas sociais. Reconhecer esse legado implica considerar os meandros pelos quais a sociedade se organiza, favorecendo o debate acerca de suas continuidades e rupturas com o processo de colonização e de racialização com vistas à transformação futura de suas estruturas de dominação e de desumanização.

\section{REFERÊNCIAS}

BUCK-MORSS, Susan. Hegel, Haití y la historia universal. México: Fondo de Cultura Económica, 2013.

BUTLER, Judith. Quadros de guerra: quando a vida é passível de luto? Rio de Janeiro: Civilização Brasileira, 2015. CÉSAIRE, Aimé. Discurso sobre o colonialismo. Portugal: Livraria Sá da Costa Editora, 1978.

CHAKRABARTY, Dipesh. Provincializing Europe: postcolonial thought and historical difference. USA: Princeton University Press, 2000.

CICCARIELLO-MAHER, George. Decolonizing dialectics. Durham: Duke University Press, 2017. 


\section{Humanos e \\ Democracia}

COULTHARD, Glen Sean. Red skin, white masks: rejecting the colonial politics of recognition. Minnesota: University of Minnesota Press, 2014.

DAVIS, Angela. Mulheres, raça e classe. São Paulo: Boitempo, 2016.

DERRIDA, Jacques. Da gramatologia. São Paulo: Perspectivas, 2008.

DU BOIS, W. E. B. As almas da gente negra. Rio de Janeiro: Lacerda Editores, 1999.

DUSSEL, Enrique. The underside of modernity: Apel, Ricoeur, Rorty, Taylor, and the philosophy of liberation. New York: Humanity Books, 1996.

DUSSEL, Enrique. 1492: o encobrimento do outro (a origem do mito da modernidade). Petrópolis: Vozes, 1993.

FANON, Frantz. Os condenados da terra. São Paulo: Civilização Brasileira, 1968.

FANON, Frantz. Pele negra, máscaras brancas. Salvador: Edufba, 2008.

FOSTER, Rainer. Contextos da justiça. São Paulo: Boitempo, 2010.

FRASER, Nancy. Da redistribuição ao reconhecimento? Dilemas da justiça na era pós-socialista. In: SOUZA, Jessé (org.). Democracia hoje: novos desafios para a teoria democrática contemporânea. Brasília: Edunb, 2001.

GONZÁLEZ, Lélia. A categoria político-cultural da amefricanidade. Tempo Brasileiro, Rio de Janeiro, n. 92-93, p. 69-82, jan./jun. 1988.

GORDON, Lewis. Disciplinary decadence: living thought in trying times. London: Paradigms Publishers, 2006.

GORDON, Lewis. An introduction to Africana philosophy. Cambridge: Cambridge University Press, 2008.

HEGEL, Friedrich. Filosofia da história. Brasília: Edunb, 2010.

HEGEL, Friedrich. Fenomenologia do espirito. Petrópolis: Vozes; Bragança Paulista: Editora Universitária São Francisco, 2014.

HONNETH, Axel. Luta por reconhecimento: a gramática moral dos conflitos sociais. São Paulo: Ed. 34, 2009.

HONNETH, Axel. O direito da liberdade. São Paulo: Martins Fontes, 2015.

JAMES, C. L. R. Os jacobinos negros: Toussaint L'Ouverture e a revolução de São Domingo. São Paulo: Boitempo, 2010.

KYMLICKA, Will. Liberalism, community and culture. New York: Oxford University Press, 1989.

MBEMBE, Achille. Necropolítica. Madrid: Ediciones Melusina, 2011.

NASCIMENTO, Abdias. O genocídio do negro brasileiro: processo de um racismo mascarado. São Paulo: Perspectivas, 2016.

QUIJANO, Anibal. "Colonialidade del poder, eurocentrismo y América Latina". In: Cuestiones y horizontes: de la dependencia histórico-estructural a la colonialidad/descolonialidad del poder. Ciudad Autónoma de Buenos Aires: Clacso, 2014.

SANDEL, Michael. Justiça: o que é fazer a coisa certa. Rio de Janeiro: Civilização Brasileira, 2011.

TAIAIAKE, Alfred. Wasase: indigenous pathways of action and freedom. Toronto: University of Toronto Press, 2005.

TAIAIAKE, Alfred. Peace, power, righteousness: an indigenous manifesto. New York: Oxford University Press, 2009.

TAIAIAKE, Alfred; REGAN, Paulette. Unsettling the settler within: indian residential schools, truth telling, and reconciliation in Canada. Vancouver: UBC Press, 2011.

TAYLOR, Charles. "The politics of recognition". In: GUTMANN, Amy (org.). Multiculturalism: examining the politics of recognition. Princeton: Princeton University Press, 1994.

TROUILLOT, Michel-Trouillot. Silencing the past: power and the production of history. Boston: Beacon Press, 1995. 